\title{
Are American Pikas (Ochotona princeps) in the Canadian Rockies Vulnerable to Climate Change?
}

\author{
CHRISTOPHER C. SHANK
}

Alberta Biodiversity Monitoring Institute, CW 405 Biological Sciences Building, University of Alberta, Edmonton, Alberta T6G 2E9 Canada; email: ccshank@gmail.com

Shank, Christopher C. 2015. Are American Pikas (Ochotona princeps) in the Canadian Rockies vulnerable to climate change? Canadian Field-Naturalist 129(3): 254-262.

The American Pika (Ochotona princeps) is vulnerable to climate change as a result of its dependence on cool, moist conditions. Most research on climatic determinants of American Pika distribution has been done in the United States where conditions are different from those in the higher-latitude pika ranges of the Canadian Rockies. I examined recent (1980-2009) and future (2050s and 2080s) average and maximum mean summer temperatures for 114 current American Pika locations in Alberta to assess whether future conditions are likely to place these animals at risk. At all current sites, mean summer temperatures (MSTs) in the 2050s are expected to be below that chosen by the United States Fish and Wildlife Service as a threshold for at-risk status of O. princeps. By the 2050s, most current American Pika locations have sufficient elevation within $5 \mathrm{~km}$ to allow individuals to migrate vertically to reach habitat with MST similar to that of their current location. Even in the 2080s, almost all current sites have sufficient elevation within $5 \mathrm{~km}$ to maintain extreme single-year and average MSTs lower than the highest values recorded at those sites in the recent past $\left(13.9^{\circ} \mathrm{C}\right.$ and $12.5^{\circ} \mathrm{C}$ respectively). However, by the $2080 \mathrm{~s}$ under an extreme greenhouse gas emissions scenario, only $34 \%$ of current pika sites will allow for such migration. Although considerable uncertainty remains, particularly with respect to availability of habitat, these results suggest that American Pika populations in Alberta will likely be capable of persisting throughout this century, although their survival will depend increasingly on successful vertical migration.

Key Words: American Pika; Ochotona princeps; Alberta; climate change; vulnerability; vertical migration; Rocky Mountains

\section{Introduction}

The American Pika (Ochotona princeps) has been variously described as a "poster child" (Hannibal 2012), "candidate indicator species" (Beever and Smith 2013), "sentinel species" (Wilkening et al. 2013, 2015), and "harbinger" (Smith et al. 2004) for the effects of climate change on biodiversity. Concerns over the effects of climate change on pikas arise from several sources including observations of population disappearance (Beever et al. 2003, 2011; Stewart et al. 2015), elevational retreat (Beever et al. 2003, 2011; Grayson 2005; Millar and Westfall 2010), susceptibility to acute (MacArthur and Wang 1974; Smith 1974a) and chronic heat stress (Beever et al. 2010; Wilkening et al. 2011; Stewart et al. 2015), increasing frequency of low precipitation and snowpack (Erb et al. 2011; Beever et al. 2013; Jeffress et al. 2013), limited dispersal ability (Seppänen et al. 2012; Beever and Smith 2013), restriction to areas of permafrost (Hafner 1993, 1994; Millar and Westfall 2010; Wilkening et al. 2015), dependence on higher elevations (Rodhouse et al. 2010), and habitat change (COSEWIC 2011).

As a result of such research, the United States Fish and Wildlife Service (USFWS) was petitioned to list the American Pika under the Endangered Species Act, but concluded that it is currently not endangered or threatened in the United States (USFWS 2010), a decision that some consider to be politically motivated (Holtcamp 2010). Although the American Pika has not been assessed by the Committee on the Status of Endangered Wildlife in Canada (COSEWIC), in 2011, the closely related but the allopatric Collared Pika (Ochotona collaris) of the Yukon, Northwest Territories, and Alaska was assessed as "special concern" by COSEWIC based largely on the potential for negative impacts of climate change, particularly reduction in suitable alpine habitat and increase in distance between habitat patches (COSEWIC 2011).

Most research on the American Pika's adaptations to climate change has been done in the United States; Canadian studies are limited to MacArthur and Wang (1973, 1974), Henry et al. (2012a,b), and Henry and Russello (2013). The Canadian Rockies can generally be characterized as having more contiguous high-elevation areas, cooler temperatures, longer winters, and more persistent snowpacks than in the United States.

It is largely accepted that, given suitable habitat and adequate forage, American Pika distribution is primarily determined by climatic factors, although there is no consensus on the particular factors. Recent efforts to establish a climatic envelope have used extensive data sets and sophisticated statistical techniques (Erb et al. 2011; Calkins et al. 2012; Ray et al. 2012; Jeffress et al. 2013; Erb et al. 2014; Stewart et al. 2015), but a clear understanding of the factors limiting pika distribution remains elusive. Suggestions from one or more authors have included elevation, aspect, mean annual temperature, acute heat stress, acute cold stress, chronic heat stress, precipitation, and snowpack. Non-climatic factors, such as talus type, amount of suitable talus upslope of current sites, habitat connectivity, vegetation abundance, and grazing, may play a role but are generally 
less predictive of pika persistence. Idiosyncrasies in climate conditions at the location of some pika populations have been noted (Simpson 2009; Jeffress et al. 2013).

Beever et al. (2010, 2013), Wilkening et al. (2011), and Stewart et al. (2015) found that chronic heat stress, determined by measuring mean summer temperature (MST) during June, July, and August, is the single best indication of whether an American Pika population will persist. The USFWS established an ambient MST of $16.2^{\circ} \mathrm{C}$ as their primary criterion for determining whether pika populations in the United States are at risk (USFWS 2010). This threshold was derived by subtracting one standard error from the observed mean summer sub-talus temperatures at which pikas were observed to disappear in the Great Basin (Beever et al. 2010). Pikas thermoregulate behaviourally by taking cover in rock crevices, suggesting that sub-talus temperature, rather than ambient temperature, is an important climatic factor to pika distribution. Sub-talus temperatures tend to be lower than ambient temperatures during the afternoon, but higher during the remainder of the day (Henry et al. 2012b), implying that mean ambient temperature is a reasonable approximation for mean sub-talus temperature.

This paper is intended to examine in detail whether summer temperatures at current American Pika locations in Alberta's Rocky Mountains are likely to remain below the level deemed to put pikas at risk and whether these pikas have sufficient vertical relief nearby to find suitable conditions by migrating up slope.

\section{Methods}

I accessed American Pika locations from the Bow Valley Naturalists' High Elevation Localized Species (HELS) project (Bow Valley Naturalists 2010) database. HELS is a citizen science project in which members of the public submit observations of American Pikas, White-tailed Ptarmigan (Lagopus leucura), Mountain Goats (Oreamnos americanus), and Hoary Marmots (Marmota caligata). Participants enter locations into the database by providing a Universal Transverse Mercator (UTM) reference or, more commonly, by clicking a point on an online map. Consequently, locations are more accurate than many museum records, in which rough coordinates are assigned to verbal location descriptions. Because most observations are made opportunistically, they reflect areas most traveled, i.e., near trails and roads. I filtered all 615 pika sites recorded in the HELS database between August 2010 and July 2014 to remove any locations outside Alberta and to ensure sample independence by removing all observations less than $3 \mathrm{~km}$ from another observation point. The $3 \mathrm{~km}$ independence limit was chosen to avoid duplicating sites resulting from inaccurate location recording, as well as reflecting dispersal distances (e.g., Meridith 2002). A total of 106 HELS locations met these criteria.
I included only two points from the extensive Global Biodiversity Information Facility (GBIF) website (GBIF n.d.). Most GBIF sites were not selected because they were within $3 \mathrm{~km}$ of an already chosen site; the coordinates were apparently estimated from general, verbal descriptions; or site examination using Google Earth suggested that it was unlikely pika habitat. Location data cited in Weimann et al. (2014) provided six additional sites for southwestern Alberta, separated by $3 \mathrm{~km}$ or more. Locations of the 114 sites are shown in Figure 1.

Elevation for each of the 114 locations and the highest points within $1,2,3,4$, and $5 \mathrm{~km}$ of each site were determined from a digital elevation model (Natural Resources Canada, n.d.) using Geospatial Modelling Environment v.0.7.0.2 tools (Hawthorne L. Beyer) and R v.2.15.2 (The R Foundation, Vienna, Austria). Site data are summarized in Table 1.

I employed ClimateWNA version 4.62 (Wang et al. 2012) to approximate historical and projected temperature variables. Historical temperatures were from 1980-2009. Future temperatures, for the 2050s (20412070 ) and the 2080s (2071-2100), were projected using an average of 23 global circulation models from Phase 3 of the World Climate Research Programme's Coupled Model Intercomparison Project (CMIP3). Although Phase 3 projections have been superseded by Phase 5 , the two suites of models produce similar projections (Knutti and Sedláček 2013). The range of uncertainty regarding future climate was addressed by employing lower (B1) and higher (A1B) greenhouse gas (GHG) emission scenarios. The A1B storyline assumes rapid economic growth, a human population peaking in midcentury, and a subsequent decline and rapid introduction of new sources and technologies entailing a balance across all sources. The B1 scenario follows the A1B storyline but puts more emphasis on global solutions to economic, social, and environmental sustainability resulting in lower levels of GHG emissions (Murdock and Spittlehouse 2011).

First, I sought to determine whether average MST in the 2050s and 2080s at current American Pika sites in Alberta would exceed the USFWS threshold of $16.2^{\circ} \mathrm{C}$.

Second, because American Pikas in the United States may be better adapted to warm conditions than in Alberta and, therefore, have a higher threshold temperature for persistence, I determined the proportion of the 114 current locations that would exceed the average MST of the warmest site in Alberta between 1980 and 2009. The highest average MST at the 114 sites was $12.5^{\circ} \mathrm{C}$, a value that can be used as a provisional threshold MST specific for the American Pika in Alberta.

Third, I reasoned that exposure to a single summer with a very high MST might lead to sudden population extinction. Using ClimateWNA, I determined that the maximum single-year MST at any Alberta site, in the years $1980-2009$, was $13.9^{\circ} \mathrm{C}$ and used this value as an Alberta-specific threshold for maximum single-year 


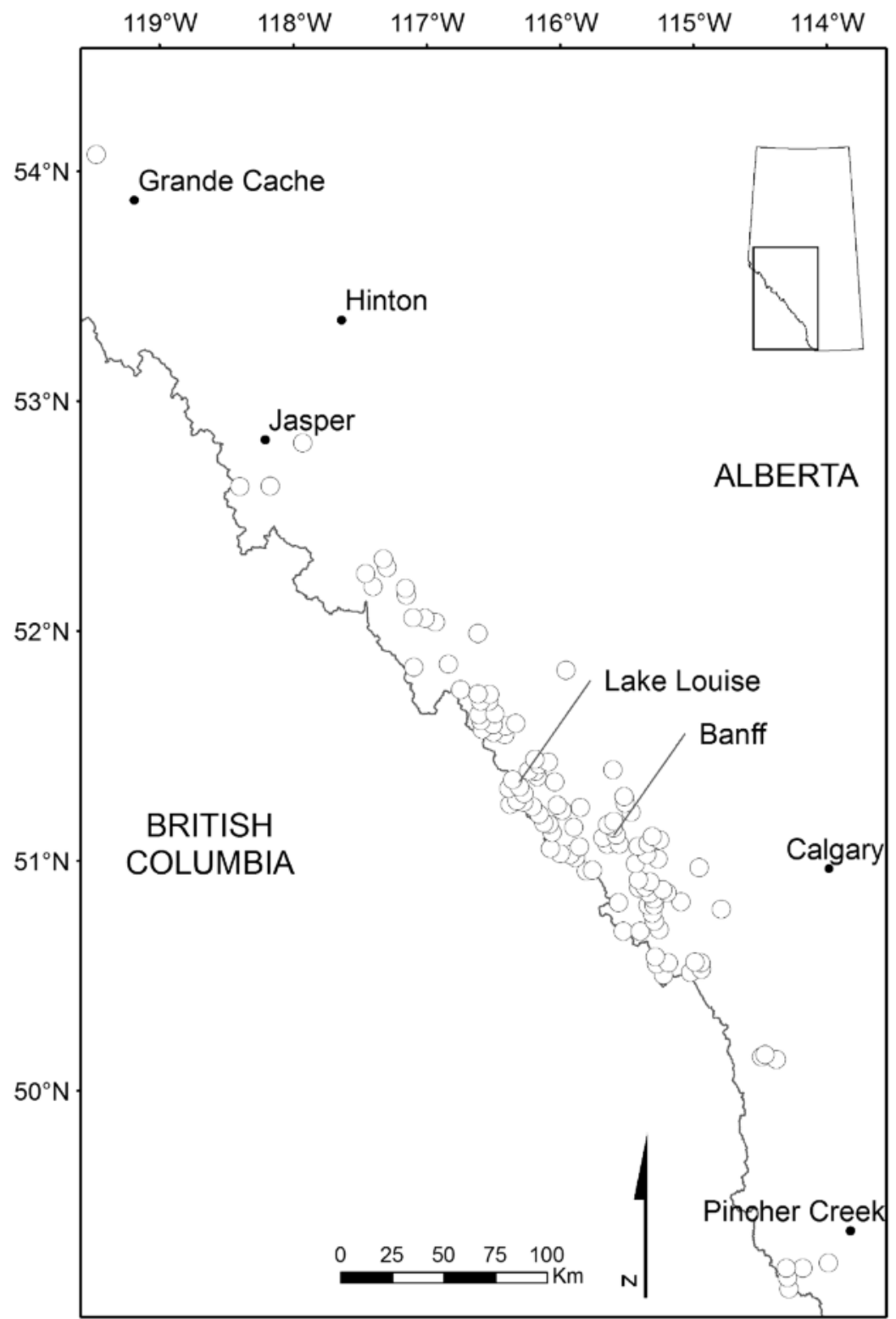

FIGURE 1. Locations of 114 reported American Pika (Ochotona princeps) observations used in the analysis (open circles).

TABLE 1. Summary of site data for the 114 American Pika (Ochotona princeps) locations in the Rocky Mountains, Alberta, used in this study.

\begin{tabular}{|c|c|c|c|c|}
\hline & Maximum & Minimum & Median & Mean \\
\hline Latitude & 54.1 & 49.2 & 51.2 & 51.3 \\
\hline Longitude & -114.1 & -119.4 & -115.8 & -115.9 \\
\hline Site elevation $(\mathrm{m})$ & 2647.8 & 1421.0 & 2196.8 & 2111.5 \\
\hline Highest elevation (m) with $1 \mathrm{~km}$ & 3065.8 & 1440.0 & 2595.6 & 2504.6 \\
\hline Highest elevation (m) with $2 \mathrm{~km}$ & 3458.3 & 1535.5 & 2796.8 & 2744.7 \\
\hline Highest elevation (m) with $3 \mathrm{~km}$ & 3487.3 & 1990.5 & 2894.0 & 2849.7 \\
\hline Highest elevation (m) with $4 \mathrm{~km}$ & 3487.3 & 2056.8 & 2969.8 & 2923.3 \\
\hline Highest elevation (m) with $5 \mathrm{~km}$ & 3487.3 & 2083.0 & 3031.5 & 2969.9 \\
\hline Lapse rate $\left({ }^{\circ} \mathrm{C} / 1000 \mathrm{~m}\right)$ & -4.2 & -5.3 & -4.6 & -4.6 \\
\hline
\end{tabular}


MST. Because ClimateWNA does not calculate values for individual future years or provide estimates of between-year variance, I estimated the highest future single-year MST by adding, for each site, the difference between the highest single-year MST for the period 1980-2009 and the average MST for the same period.

The remaining two approaches I employed were to project whether pikas in Alberta would be able to maintain the three threshold MSTs $\left(16.2^{\circ} \mathrm{C}, 12.5^{\circ} \mathrm{C}, 13.9^{\circ} \mathrm{C}\right)$ by moving to higher elevations. The question is whether the mountains near current pika locations are high enough in elevation to provide temperatures less than or equal to those experienced at current pika locations, the warmest average Alberta MST of $12.5^{\circ} \mathrm{C}$ or the maximum single-year MST of $13.9^{\circ} \mathrm{C}$. I used lapse rates to predict the elevation at which the threshold MST would occur. Lapse rates are a measure of temperature change with elevation and are a linear function of elevation, but they differ with location, season, and climate variables. For each of the 114 pika locations, I calculated lapse rate for MSTs directly from ClimateWNA outputs by regressing MST on elevation. Values varied from $-4.214^{\circ} \mathrm{C}$ to $-5.313^{\circ} \mathrm{C}$ per 1000 vertical metres (Table 1). Wang et al. (2012) describe in detail how lapse rates were developed for Climate WNA. Ray et al. (2010) discuss some of the assumptions and sources of error in estimating lapse rates, and Wang et al. (2012) note that this approach does not capture temperature effects produced by small-scale topographic effects (e.g., aspect, slope, and frost pockets). Using the calculated lapse rates, I determined the elevation required to meet the threshold MST according to the following formula:

$$
E_{f}=\left(\left(T_{f}-T_{t}\right) \cdot L^{-1}\right)+E_{c}
$$

where $E_{f}=$ elevation $(\mathrm{m})$ in the $2050 \mathrm{~s}$ and $2080 \mathrm{~s}$ required to meet the threshold MST, $T_{f}=$ future MST $\left({ }^{\circ} \mathrm{C}\right)$ at the current location, $T_{t}=$ the threshold MST $\left({ }^{\circ} \mathrm{C}\right), L=$ the lapse rate $\left(\Delta^{\circ} \mathrm{C}\right.$ per $\mathrm{m}$ of elevation gain $)$, and $E_{c}=$ the elevation (m) of the current site. The criterion for population persistence was $E_{f}$ less than the elevation of the highest point within a distance over which pikas are capable of dispersing.

American Pikas are philopatric (Smith and Ivins 1983) and have traditionally been considered to be very poor dispersers (Galbreath et al. 2009). Earlier estimates of pika dispersal distances range from $100 \mathrm{~m}$ (Smith and Weston 1990) to $300 \mathrm{~m}$ (Smith 1974a), but depend on marked animals, a technique that generally results in shorter estimates than those using later genetic approaches (Peacock 1997). More recent studies indicate a wide range of dispersal distances including $<20 \mathrm{~km}$ (Hafner 1993), $\geq 2 \mathrm{~km}$ (Zgurski and Hik 2012), 2-10 km (Peacock 1997), and 3 km (Merideth 2002). Topographic complexity, water barriers, and west-facing slopes were the major factors found to restrict pika dispersal in Oregon (Castillo et al. 2014).
Given the uncertainty in how far any particular pika population is likely to disperse, I chose to examine the highest elevations within $1,2,3,4$, and $5 \mathrm{~km}$ of current sites.

\section{Results}

Over the period 1980-2009, the average or maximum MST of $16.2^{\circ} \mathrm{C}$ that theoretically limits pika persistence in the United States was not exceeded at any of the Alberta sites (Figures 2 and 3).

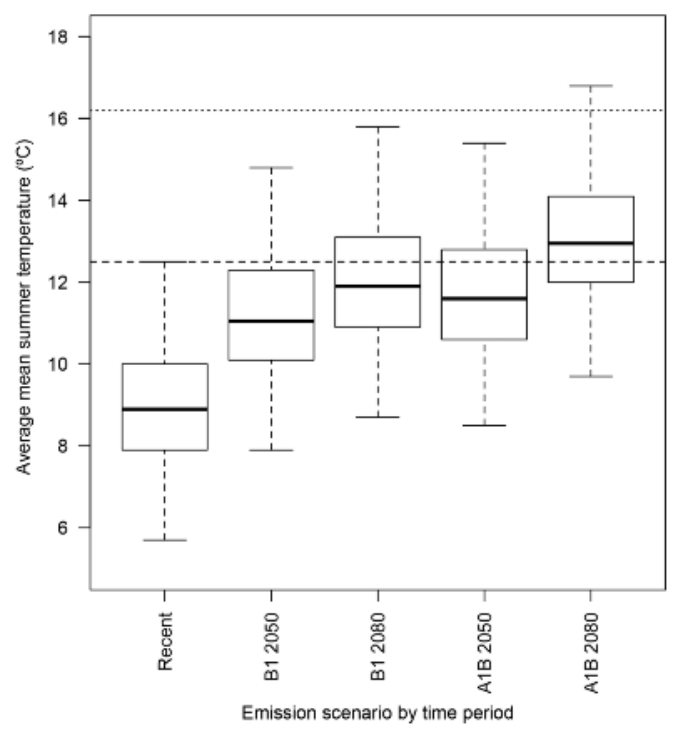

FIGURE 2. Mean summer temperatures (MSTs) averaged over the period 1980-2009 and projected average MSTs in 2050s and 2080s for lower (B1) and higher (A1B) greenhouse gas emission scenarios at 114 American Pika (Ochotona princeps) sites in Alberta. The horizontal dashed line represents the highest average MST $\left(12.5^{\circ} \mathrm{C}\right)$ in $1980-2009$ at these pika sites; the horizontal dotted line is the United States Fish and Wildlife Service risk threshold $\left(16.2^{\circ} \mathrm{C}\right)$. The bottom and top of the boxes indicate the first and third quartiles, respectively, and the heavy horizontal bar the median. The whiskers represent extreme values.

Based on the USFWS criterion for persistence (average MST $\leq 16.2^{\circ} \mathrm{C}$ ), none of the observed American Pika populations in Alberta is likely to be at risk from increased MST in the 2050s and in the 2080s under the B1 emission scenario (Figure 2). However, in the 2080s under the more extreme A1B emission scenario, the average MST is expected to exceed the threshold of $16.2^{\circ} \mathrm{C}$ at four sites $(3.5 \%)$.

If one considers that a single-year with a maximum MST $>16.2^{\circ} \mathrm{C}$ might cause extinction of American Pika populations, then pikas at six $(5.2 \%)$ of the current sites are in danger of extirpation in the 2050s under the more extreme A1B emission scenario, although 


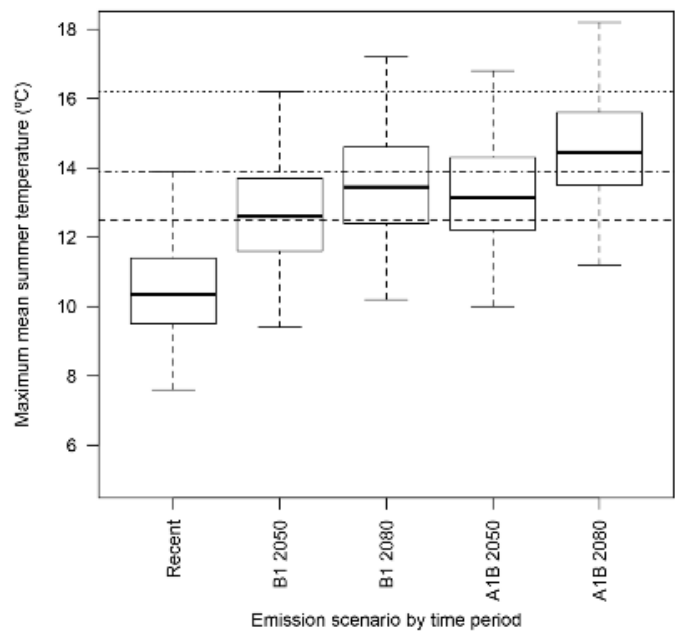

FIGURE 3. Maximum single-year mean summer temperatures (MSTs) for 1980-2009 and projected future (2050s and 2080s) extreme single-year MSTs for lower (B1) and higher (A1B) emission scenarios at 114 American Pika (Ochotona princeps) sites in Alberta. The horizontal dashed line represents the highest MST $\left(12.5^{\circ} \mathrm{C}\right)$ in 1980-2009 at these sites, the horizontal dotted line is the United States Fish and Wildlife Service risk threshold $\left(16.2^{\circ} \mathrm{C}\right)$, and the broken dashed line the highest single-year MST recorded for any site during 1980-2009. The bottom and top of the boxes indicate the first and third quartiles, respectively, and the heavy horizontal bar the median. The whiskers represent extreme values.

none are in danger under the B1 scenario. In the 2080s, four $(3.5 \%)$ and $18(15.8 \%)$ of the sites will exceed $16.2^{\circ} \mathrm{C}$ under the $\mathrm{B} 1$ and $\mathrm{A} 1 \mathrm{~B}$ scenarios, respectively (Figure 3).

Because temperatures are projected to rise throughout the range of the American Pika in Alberta, pikas will have to migrate up slope to remain at the MST of their current sites. The dispersal potential of pikas influences their ability to access suitable habitat at higher elevations. In the 2050s under the B1 emission scenario, sufficient elevation is available within $1 \mathrm{~km}$ of current sites to maintain historical average MSTs for $34.2 \%$ of sites and for $91.2 \%$ of sites within $5 \mathrm{~km}$ (Figure 4).

However, in the 2080s and under the A1B scenario, there are no sites with sufficient elevation within $1 \mathrm{~km}$ to maintain current average MSTs and only $34.2 \%$ of current sites have sufficient elevation with $5 \mathrm{~km}$ to do so (Figure 4).

Nevertheless, American Pikas at most current Alberta locations will continue to experience average MSTs less than $12.5^{\circ} \mathrm{C}$, that of the warmest current Alberta site (Figure 5, dispersal distance $=0 \mathrm{~km}$ ). With vertical migration, nearly all pikas will be able to find locations with MSTs $<12.5^{\circ} \mathrm{C}$ within $5 \mathrm{~km}$ (Figure 5 , dispersal distance $=5 \mathrm{~km}$ ).

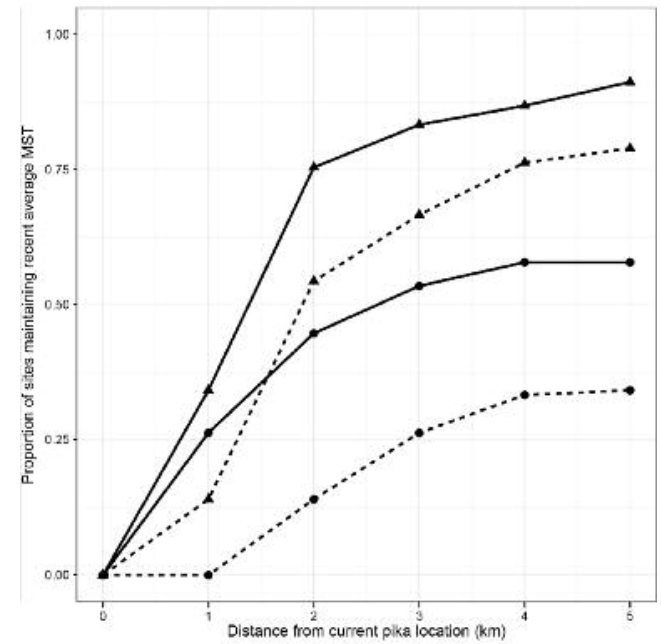

FIGURE 4. The proportion of 114 American Pika (Ochotona princeps) sites in Alberta where average mean summer temperatures are expected to remain less than or equal to those experienced between 1980 and 2009 at the current location $(0 \mathrm{~m})$ and at higher elevations within $1-5 \mathrm{~km}$. The solid lines are the projections for the 2050 s and the dotted lines for the 2080s. The lower emission scenario (B1) is indicated by circles and the higher emission scenario (A1B) by triangles.

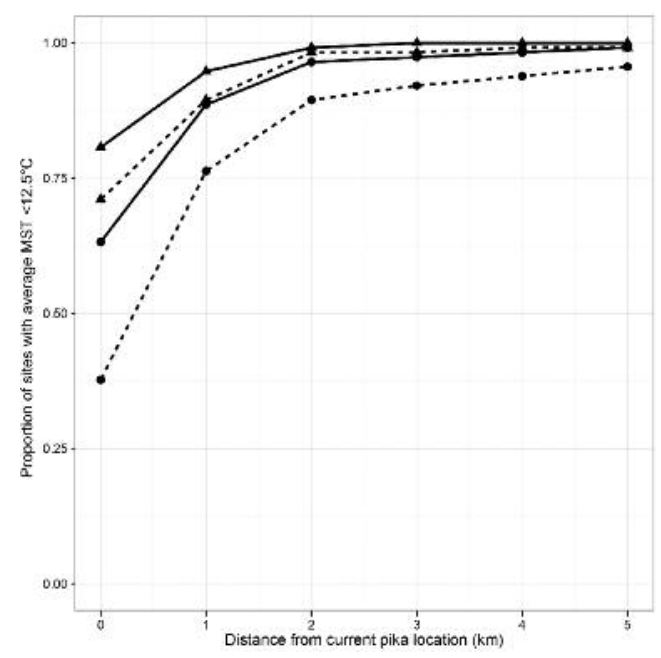

Figure 5. The proportion of 114 American Pika (Ochotona princeps) sites in Alberta where average mean summer temperature (MST) is expected to remain $\leq 12.5^{\circ} \mathrm{C}$ (i.e., the highest average MST for any site between 1980 and 2009) at the current location $(0 \mathrm{~m})$ and at higher elevations within $1-5 \mathrm{~km}$. The solid lines are the projections for the $2050 \mathrm{~s}$ and the dotted lines for the 2080s. The lower emission scenario (B1) is indicated by circles and the higher emission scenario (A1B) by triangles. 
If a single year with an MST greater than the highest single-year MST of $13.9^{\circ} \mathrm{C}$ causes population extinction, then pikas at most current sites are likely to persist into the 2050s under both emission scenarios and into the 2080s under the B1 scenario (Figure 6, distance $=$ $0 \mathrm{~km}$ ). By migrating up slope within $5 \mathrm{~km}$, almost all current pika populations will avoid extreme MSTs higher than those experienced by any Alberta population during 1980-2009 Figure 6, distance $=5 \mathrm{~km}$ ) even under the more extreme A1B scenario.

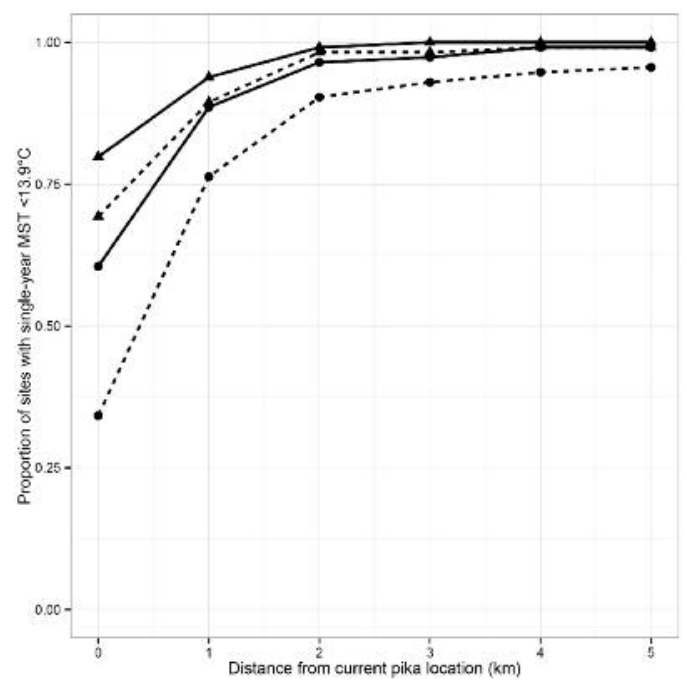

FIgURE 6. Proportion of the 114 American Pika (Ochotona princeps) locations in Alberta where single-year mean summer temperature (MST) is expected to remain $\leq 13.9^{\circ} \mathrm{C}$ (i.e., the highest single-year MST for any site in 1980-2009) at the current location (0 $\mathrm{m})$ and at higher elevations within $1-5 \mathrm{~km}$. The solid lines are the projections for the 2050s and the dotted lines for the 2080s. The lower emission scenario (B1) is indicated by circles and the higher emission scenario (A1B) by triangles.

\section{Discussion}

Based on analysis of MST alone, one can project that most current American Pika populations in Alberta will persist into the 2050s and, if GHG emissions are controlled, into the 2080s. Under the more extreme A1B emission scenario, most lower-elevation sites are likely to be abandoned by the 2080s. Up-slope migration will become increasingly important toward the end of the century, particularly if GHGs are not vigorously controlled. However, a changing climate may affect Alberta pika populations in manners not captured by analysis of MST alone.

Because of the fragmented nature of talus habitat, American Pikas exhibit classic metapopulation dynam- ics (Hanski 1998), in which regional populations may remain stable while local groups may disappear and their sites become recolonized. Consequently, pikas have been the subject of numerous empirical and theoretical metapopulation explorations (e.g., Peacock and Smith 1997). Climate change is likely to affect the quality of habitat patches, distance between suitable patches, and population demographics. Therefore, the balance between population extinction and recolonization may be altered in unpredictable ways.

This analysis addresses only the proximal effects of extreme and average MSTs on American Pika populations and does not consider the effects of climate change on habitat. In the Canadian Rockies, as elsewhere, talus slopes are the most common pika habitat and are usually formed by debris eroding from steep bedrock faces and collecting at the cliff foot where slope angle eases (Bithell et al. 2014). There is likely to be less such talus habitat at higher elevations where suitable temperatures may exist in the future.

American Pikas also require suitable vegetation within close proximity of talus fields. Vegetation can be expected to move up slope rapidly with warming temperatures (Schneider 2013). This is likely to result in loss of some meadow habitat through introgression of trees and shrubs and the creation of new meadow habitat at now-barren higher elevations, if soil conditions allow. Loss and addition of suitable habitat are likely to alter pika metapopulation dynamics in unpredictable ways. Climate-induced habitat loss was the major consideration in listing the Collared Pika as "special concern" in Canada (COSEWIC 2011).

Of particular uncertainty is the role of snow and cold in determining the distribution of American Pikas. Jeffress et al. (2013) speak of a "Goldilocks effect," whereby pikas in the western United States are squeezed between hot conditions at low elevations and cold, wet conditions at high elevations. My analysis addressed only the former situation. Snow blanketing the talus acts to insulate pikas from extreme cold. Beever et al. (2010) found below-talus temperatures to be colder in the absence of snow, and acute cold stress (defined as number of days with below-talus temperatures less than $-5^{\circ} \mathrm{C}$ ) to be among the better predictors of pika persistence in the Great Basin. Morrison and Hik $(2007,2010)$ reported the collapse of a population of Collared Pikas in the Yukon by $90 \%$ between 1998 and 2003, a period with later spring snowmelt associated with negative Pacific Decadal Oscillation values. Unfortunately, no suitable snowpack data exist that would allow for examination of these relationships for American Pika in Alberta.

American Pikas might also adapt to a warmer future climate. In a study of a population at the northern edge of the species range in west-central British Columbia, Henry et al. (2012a) concluded that there is less genetic variation in northern populations than in more southerly ones, consistent with recolonization after recent de- 
glaciation. No heterozygosity values are known for the species in Alberta. The effect of reduced genetic diversity on the ability of pikas to adapt to climate change is not known (Henry et al. 2012a).

Given the limited range of the American Pika in Alberta and a relatively poor understanding of impacts of a changing climate on this species in Alberta, a welldesigned and consistent monitoring program should be implemented in the province, both outside and inside the national parks, to provide an early indicator of changes in American Pika population numbers. Pika census methods are discussed by Morrison and Hik (2010), Millar and Westfall (2010), Timmins and Whittington (2011), Moyer-Horner et al. (2012), Rodhouse et al. (2010), and Timmins et al. (2013). In addition, research is needed on the climate determinants of pika distribution in Alberta. Beever et al. (2011) and Beever and Smith (2013) provide a research priority list that includes multiscale sampling; better understanding of the relative effects of acute cold stress, acute heat stress, and chronic heat stress; closely examining pika use of micro-climates; determining how food selectivity indices may vary under different conditions; and detailed analysis of the additive or synergistic roles played by simultaneous climate-related stressors.

\section{Acknowledgements}

Jon Ball of the Bow Valley Naturalists kindly provided me with the raw HELS data. Brad Weimann pointed me to pika location data from southern Alberta. My thanks to Amy Nixon for producing the map, providing the elevation data, and commenting on early drafts of the paper. Shawn Morrison provided insightful comments on an earlier version of the paper. The paper benefitted greatly from suggestions made by two peer reviewers and the journal editors.

This report is a product of the Biodiversity Management and Climate Change Adaptation Project (http:// www.biodiversityandclimate.abmi.ca) led by the Alberta Biodiversity Monitoring Institute. The project receives its core funding from the Climate Change and Emissions Management Corporation (http://ccemc.ca).

\section{Documents Cited}

Beever, E., and A. T. Smith. 2011. Ochotona princeps. IUCN Red List of Threatened Species, version 2015.2. International Union for Conservation of Nature and Natural Resources, Cambridge, UK. Accessed July 2015. http://www .iucnredlist.org/details/41267/0.

Bow Valley Naturalists. 2010. High elevation species map. Bow Valley Naturalists, Banff-Canmore, Alberta, Canada. Accessed December 2014. http://www.bowvalleynatural ists.org/hels/archive.php.

COSEWIC (Committee on the Status of Endangered Wildlife in Canada). 2011. COSEWIC assessment and status report on the Collared Pika Ochotona collaris in Canada. Government of Canada, Ottawa, Ontario, Canada. Accessed October 2014. http://www.registrelep-sararegistry .gc.ca/default.asp?lang=En\&n=2C5BA237-1.
GBIF (Global Biodiversity Information Facility). n.d. Free and open access to biodiversity data. GBIF, Copenhagen, Denmark. Accessed June 2014. http://www.gbif .org.

Hannibal, M. E. 2012. Pika: the alpine poster child for climate change. Outside, September 18. Accessed July, 2014. http://www.outsideonline.com/blog/outdoor-adventure /nature/pika-the-alpine-poster-child-for-climate-change .html.

Natural Resources Canada. n.d. Geospatial data extraction. Natural Resources Canada, Ottawa, Ontario, Canada. Accessed October 2014. http://geogratis.gc.ca/site/eng/extrac tion.

Schneider, R. R. 2013. Alberta's natural subregions under a changing climate: past, present, and future. Alberta Biodiversity Monitoring Institute, Edmonton, Alberta, Canada. Accessed March 2015. http://biodiversityandclimate.abmi .ca/wp-content/uploads/2015/01/Schneider_2013_Alberta NaturalSubregionsUnderaChangingClimate.pdf.

Timmins, J., A. Forshner, and J. Whittington. 2013. Banff National Park pika monitoring 2013: summary report. Banff National Park of Canada, Parks Canada Agency, Banff, Alberta, Canada. Accessed July 2014. http://www .bowvalleynaturalists.org/resources/Pika-Monitoring-Sum mary-Report-2013-Banff-National-Park.pdf.

Timmins, J., and J. Whittington. 2011. Pika monitoring in Banff National Park: 2011 pilot study. Banff National Park of Canada, Parks Canada Agency, Banff, Alberta, Canada. Accessed July 2014. http://www.bowvalleynaturalists.org /resources/HOME/Pika-Monitoring-Report-for-BNP-2011 -Final.pdf.

USFWS (United States Fish and Wildlife Service). 2010. Endangered and threatened wildlife and plants; 12-month finding on a petition to list the American Pika as threatened or endangered. Federal Register 75(26): 6437-6471. Accessed June 2014. http://www.gpo.gov/fdsys/pkg/FR-2010 $-02-09 /$ pdf/2010-2405.pdf.

\section{Literature Cited}

Beever, E. A., P. F. Brussard, and J. Berger. 2003. Patterns of apparent extirpation among isolated populations of pikas (Ochotona princeps) in the Great Basin. Journal of Mammalogy 84: 37-54.

Beever, E. A., C. Ray, P. W. Mote, and J. L. Wilkening. 2010. Testing alternative models of climate-mediated extirpations. Ecological Applications 20: 164-178.

Beever, E. A., C. Ray, J. L. Wilkening, P. F. Brussard, and P. W. Mote. 2011. Contemporary climate change alters the pace and drivers of extinction. Global Change Biology 17: 2054-2070.

Beever, E. A., S. Z. Dobrowski, J. Long, A. R. Mynsberge, and N. B. Piekielek. 2013. Understanding relationships among abundance, extirpation, and climate at ecoregional scales. Ecology 94: 1563-1571.

Bithell, M., K. S. Richards, and E. G. Bithell. 2014. Simulation of scree-slope dynamics: investigating the distribution of debris avalanche events in an idealized two-dimensional model. Earth Surface Processes and Landforms 39: 1601-1610.

Calkins, M. T., E. A. Beever, K. G. Boykin, J. K. Frey, and M. C. Andersen. 2012. Not-so-splendid isolation: modeling climate-mediated range collapse of a montane mammal Ochotona princeps across numerous ecoregions. Ecography 35: 780-791. 
Castillo, J. A., C. W. Epps, A. R. Davis, and S. A. Cushman. 2014. Landscape effects on gene flow for a climate-sensitive montane species, the American pika. Molecular Ecology 23: 843-856.

Erb, L. P., C. Ray, and R. Guralnick. 2011. On the generality of a climate-mediated shift in the distribution of the American pika (Ochotona princeps). Ecology 92: 17301735.

Erb, L. P., C. Ray, and R. Guralnick. 2014. Determinants of pika population density versus occupancy in the Southern Rocky Mountains. Ecological Applications 24: 429435.

Galbreath, K. E., D. J. Hafner, and K. R. Zamudio. 2009. When cold is better: climate-driven elevation shifts yield complex patterns of diversification and demography in an alpine specialist (American pika, Ochotona princeps). Evolution 63: 2848-2863.

Grayson, D. K. 2005. A brief history of Great Basin pikas. Journal of Biogeography 32: 2103-2111.

Hafner, D. J. 1993. North American pika (Ochotona princeps) as a late Quaternary biogeographic indicator species. Quaternary Research 39: 373-380.

Hafner, D. J. 1994. Pikas and permafrost: post-Wisconsin historical zoogeography of Ochotona in the southern Rocky Mountains, U.S.A. Arctic and Alpine Research 26: 375382.

Hanski, I. 1998. Metapopulation dynamics. Nature 396: 4149.

Henry, P., Z. Sim, and M. A. Russello. 2012a. Genetic evidence for restricted dispersal along continuous altitudinal gradients in a climate change-sensitive mammal: the American pika. PloS One 7(6): e39077.

Henry, P., A. Henry, and M. A. Russello. 2012b. Variation in habitat characteristics of American pikas along an elevation gradient at their northern range margin. Northwest Science 86: 346-350.

Henry, P., and M. A. Russello. 2013. Adaptive divergence along environmental gradients in a climate-change-sensitive mammal. Ecology and Evolution 3: 3906-3917.

Holtcamp, W. 2010. Silence of the pikas. BioScience 60: 8-12.

Jeffress, M. R., T. J. Rodhouse, C. Ray, S. Wolff, and C. W. Epps. 2013. The idiosyncrasies of place: geographic variation in the climate-distribution relationships of the American pika. Ecological Applications 23: 864-878.

Knutti, R., and J. Sedláček. 2013. Robustness and uncertainties in the new CMIP5 climate model projections. Nature Climate Change 3: 369-373.

MacArthur, R. A., and L. C. H. Wang. 1973. Physiology of thermoregulation in the pika, Ochotona princeps. Canadian Journal of Zoology 51: 11-16.

MacArthur, R. A., and L. C. H. Wang. 1974. Behavioral thermoregulation in the pika Ochotona princeps: a field study using radiotelemetry. Canadian Journal of Zoology 52: 353-358.

Merideth, S. J. 2002. The impact of habitat spatial structure on pika (Ochotona princeps) dispersal dynamics. M.Sc. thesis, University of Nevada, Reno, Nevada, USA.

Millar, C. I., and R. D. Westfall. 2010. Distribution and climatic relationships of the American pika (Ochotona princeps) in the Sierra Nevada and western Great Basin, U.S.A.; periglacial landforms as refugia in warming climates. Arctic, Antarctic, and Alpine Research 42: 76-88.

Morrison, S. F., and D. S. Hik. 2007. Demographic analysis of a declining pika Ochotona collaris population: linking survival to broad-scale climate patterns via spring snowmelt patterns. Journal of Animal Ecology 76: 899-907.

Morrison, S. F., and D. S. Hik. 2010. When? Where? And for how long? Census design considerations for an alpine lagomorph, the collared pika (Ochotona collaris). Pages 103113 in Lagomorph Biology: Evolution, Ecology and Conservation. Edited by P. C. Alves, N. Ferrand, and K. Hackländer. Springer, Berlin, Germany.

Moyer-Horner, L., M. M. Smith, and J. Belt. 2012. Citizen science and observer variability during American pika surveys. Journal of Wildlife Management 76: 1472-1479.

Murdock, T. Q., and D. L. Spittlehouse. 2011. Selecting and using climate change scenarios for British Columbia. Pacific Climate Impacts Consortium, University of Victoria, Victoria, British Columbia, Canada.

Peacock, M. M. 1997. Determining natal dispersal patterns in a population of North American pikas (Ochotona princeps) using direct mark-resight and indirect genetic methods. Behavioral Ecology 8: 340-350.

Peacock, M. M., and A. T. Smith. 1997. The effect of habitat fragmentation on dispersal patterns, mating behavior, and genetic variation in a pika (Ochotona princeps) metapopulation. Oecologia 112: 524-533.

Ray, A. J., J. J. Barsugli, K. E. Wolter, and J. K. Eischeid. 2010. Rapid-response climate assessment to support the FWS status review of the American pika. Technical report. United States Fish and Wildlife Service and National Oceanic \& Atmospheric Administration Earth System Research Laboratory, Boulder, Colorado, USA.

Ray, C., E. A. Beever, and S. R. Loarie. 2012. Retreat of the American pika: up the mountain or into the void. Pages 245-270 in Wildlife Conservation in a Changing Climate. Edited by J. F. Brodie, E. Post, and D. F. Doak. University of Chicago Press, Chicago, Illinois, USA.

Rodhouse, T. J., E. A. Beever, L. K. Garrett, K. M. Irvine, M. R. Jeffress, M. Munts, and C. Ray. 2010. Distribution of American pikas in a low-elevation lava landscape: conservation implications from the range periphery. Journal of Mammalogy 91: 1287-1299.

Seppänen, A., K. Parvinen, and J. D. Nagy. 2012. Evolution of dispersal in American pika (Ochotona princeps) metapopulations. Evolutionary Ecology Research 14: 1-29.

Simpson, W. G. 2009. American pikas inhabit low-elevation sites outside the species' previously described bioclimatic envelope. Western North American Naturalist 69: 243-250.

Smith, A. T., and B. L. Ivins. 1983. Colonization in a pika population: dispersal vs philopatry. Behavioral Ecology and Sociobiology 13: 37-47.

Smith, A. T., and M. L. Weston. 1990. Ochotona princeps. Mammalian Species 352: 1-8.

Smith, A. T., L. Weidong, and D. S. Hik. 2004. Pikas as harbingers of global warming. Species 41: 4-5.

Smith, A. T. 1974a. The distribution and dispersal of pikas: consequences of insular population structure. Ecology 55 : 1112-1119.

Smith, A. T. 1974b. The distribution and dispersal of pikas: influences of behavior and climate. Ecology 55: 13681376.

Stewart, J. A. E., J. D. Perrine, L. B. Nichols, J. H. Thorne, C. I. Millar, K. E. Goehring, C. P. Massing, and D. H. Wright. 2015. Revisiting the past to foretell the future: summer temperature and habitat area predict pika extirpations in California. Journal of Biogeography 42: 880-890

Wang, T., A. Hamann, D. L. Spittlehouse, and T. Q. Murdock. 2012. ClimateWNA - high-resolution spatial 
climate data for western North America. Journal of Applied Meteorology and Climatology 51: 16-29.

Weimann, B., M. A. Edwards, and C. N. Jass. 2014. Identification of the baculum in American pika (Ochotona princeps: Lagomorpha) from southwestern Alberta, Canada. Journal of Mammalogy 95: 284-289.

Wilkening, J. L., C. Ray, E. A. Beever, and P. F. Brussard. 2011. Modeling contemporary range retraction in Great Basin pikas (Ochotona princeps) using data on microclimate and microhabitat. Quaternary International 235: $77-$ 88 .
Wilkening, J. L., C. Ray, and K. L. Sweazea. 2013. Stress hormone concentration in Rocky Mountain populations of the American pika (Ochotona princeps). Conservation Physiology 1: cot027.

Wilkening, J. L., C. Ray, and J. Varner. 2015. Relating subsurface ice features to physiological stress in a climate sensitive mammal, the American pika (Ochotona princeps). PlosOne 10(3): e0119327.

Zgurski, J. M., and D. S. Hik. 2012. Polygynandry and evensexed dispersal in a population of collared pikas, Ochotona collaris. Animal Behaviour 83: 1075-1082.

Received 14 November 2014

Accepted 20 May 2015 